Research Article

\title{
The effect of change in design of vibrating chamber for An Experimental analysis for sea sand as an Abrasive material in an Abrasive Jet machining Process for mild steel Nozzle
}

\author{
N. S. Pawar ${ }^{\dot{A}^{*}}$, R.R. Lakhe ${ }^{\dot{B}}$ and R. L. Shrivastava ${ }^{\dot{C}}$ \\ ${ }^{\dot{A}}$ Department of Mechanical Engg, Government Polytechnic Nagpur, Maharastra state, India \\ ${ }^{\dot{B}}$ Director, shreyas Quality Management system, Training and consultancy Maharastra State,India \\ ${ }^{\mathrm{C}}$ Professor in Mech Engg Dept., Yashwanrao chavan college of Engg. Nagpu
}

Accepted 10 January 2014, Available online 01 February 2014, Special Issue-2, (February 2014)

\begin{abstract}
Invention was made to create the needs. Abrasive jet machining is also known as abrasive micro-blasting and it is traditional process. A number of investigations were carried out by imminent personality but no detailed information and design has provided about design of vibration chamber or mixing chamber. This change in shape gives better turbulence to abrasive particles and velocity of abrasive particles. This non sticking characteristic also gives the better effect of erosion of material on work piece and scattering of particle towards objects. The parameter material removal rate, standoff distance, variable pressure used for this experimental study. The work carried out with traditional nozzle like tungsten carbide, silicon carbide which available in market and new proposed mild steel nozzle. Powder flow rate is controlled by the amplitude of mixing chamber. The performance of sea sand in vibrating chamber show by using polynomial where $R$-square values very near to 1 i.e. 0.9687 using variable parameter
\end{abstract}

Keywords: vibrating chamber, Abrasive Jet Machine, sea sand, Nozzle, glass.

\section{Introduction}

The development of new method has always been Endeavour of engineering personnel and scientists. The main ideas behind the such Endeavour's have generally been the economic consideration, replacement of existing manufacturing methods by more efficient and quicker ones, achievement of higher accuracies and quality of surface finished, adoptability of cheaper material in place of costlier ones and developing a method of machining such material cannot be easily machined through the conventional methods etc of all those reasons. This process consists of directing a stream of fine abrasive grains, mixed with compressed air at pressure ranging from $5 \mathrm{~kg} / \mathrm{cm}^{2}$ to $12 \mathrm{~kg} / \mathrm{cm}^{2}$. These particles impinge on the work surface at high speed and the erosion caused by their impact enables the removal metal.

The relative motion between the work piece and nozzle is obtained by cams, the compressed air along with the entrained abrasive particles of size 100-150 micron passes on the nozzle having its tip of tungsten carbide, alumina, and mild steel nozzle. Fine grained sea sand abrasive of grain size 100 to 150 microns powder is filled in a vibrating chamber, called mixing chamber. The air at high pressure is forced into this chamber, the pressure of gas varying from 5 to $12 \mathrm{~kg} / \mathrm{cm}^{2}$ it is passed through the mixing chamber vibrating at $50 \mathrm{c} / \mathrm{s}$. from the mixing

*Corresponding author: N. S. Pawar

DOI: http://dx.doi.org/10.14741/ijcet/spl.2.2014.109 chamber, The diameter around of $1 \mathrm{~mm}$ to $2 \mathrm{~mm}$ with a velocity of $150-300 \mathrm{~m} / \mathrm{sec}$. This process is mainly employed for such a machining work which is otherwise difficult by referring no. of researcher's studies. This high velocity jet is then directed on the work piece surface and small pit of material gets loosened and then removed due to flow. Again the fresh surface gets exposed to the jet for further erosion. Torsional vibration is angular vibration of an object commonly a shaft along its axis of rotation. The fundamentals of vibration analysis can be understood by studying the simple mass-spring-damper model.

\section{Vibrating Chamber as per design}

As per the changes in the design of vibrating chamber we have selected the cylindrical vibrating chamber due to its several advantages. The dimension 160x110x4 (mm). The high compressed air inside the chamber which the cylinder walls and cover plate have to withstands. It was design and selected in a such way that the cover plate and cylinder wall should not bend due to the internal pressure and total leakages were avoided and check the dimensions by considering the cover plate and the cylinder wall subjected to uniform pressure. The equation from design data for uniform pressure

$\mathbf{T}=\mathbf{a} \times \mathbf{b} \times \mathbf{c}_{3}\left[\mathbf{p} /\left\{\boldsymbol{\sigma} 1\left(\mathbf{a}^{2}+\mathbf{b}^{2}\right)\right\}^{1 / 2}\right.$

Where, $\mathrm{p}=$ uniform pressure, $\mathrm{a}=$ length of the plate in $\mathrm{mm}, \mathrm{b}=$ breadth of plate in $\mathrm{mm}, \mathrm{c}_{3}=$ co-efficient $=0.49$ from table

576 | International Conference on Advances in Mechanical Sciences 2014 
$\mathrm{T}=0.49 \times 230 \times 160 \times[0.8 /\{(2302+1602)\}]^{1 / 2}$

$\mathrm{T}=4.85 \mathrm{~mm}$

$\mathrm{T}=5 \mathrm{~mm}$

Vibrating chamber is a cylinder piece of M.S. pipe with rectangular base and head. The cylinder of dimension 160 x $110 \times 4 \mathrm{~mm}$ was taken from the pipe having the same size and shape. The rectangular M.S. plate of dimensions $(235 \times 185 \times 4)$ was also cut from M.S. sheet then by shaping the edges is made right angle. Two holes of inlet of compressed air and one hole for outlet are provided The design vibrating chamber has shown below.

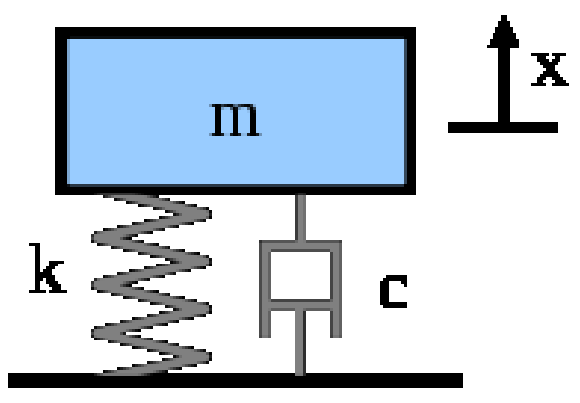

Fig.1. Mass spring damper model
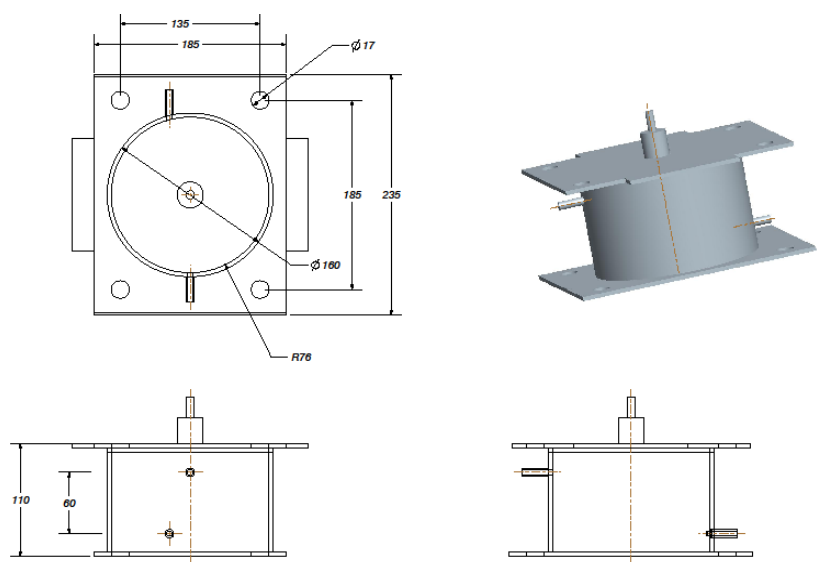

Fig.2: View of vibrating chamber

\section{Cam for vibration chamber}

Cam followers come in a vast array of different configurations, A cam follower, also known as a track follower, is a specialized type of roller bearing designed to follow cams.

The eccentricity of cam $=10 \mathrm{~mm}$

Lift of follower $\quad=20 \mathrm{~mm}$

Amplitude of Vibration $\quad=10 \mathrm{~mm}$

External Diameter of cam $=60 \mathrm{~mm}$

Diameter of Shaft $\quad=20 \mathrm{~mm}$

The thickness of cam $=16 \mathrm{~mm}$

External Diameter of Roller $=20 \mathrm{~mm}$

Thickness of Roller $\quad=16 \mathrm{~mm}$

Pin Diameter $\quad=16 \mathrm{~mm}$

The follower is roller follower

External Diameter $\quad=20 \mathrm{~mm}$

Thickness $\quad=16 \mathrm{~mm}$

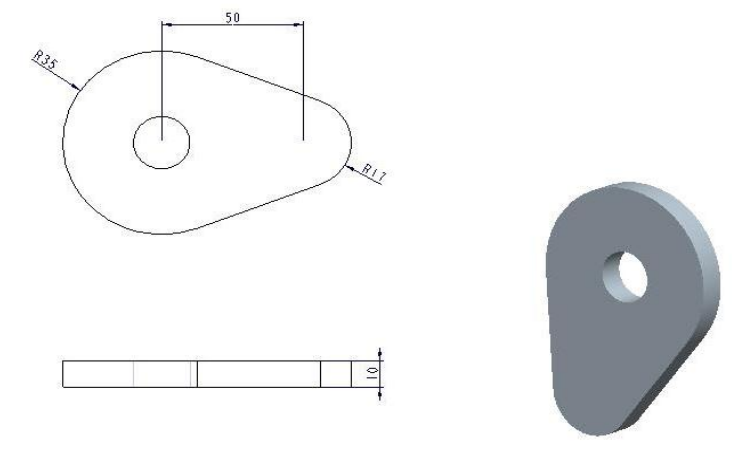

Cam

Fig.3: cam for vibration chamber

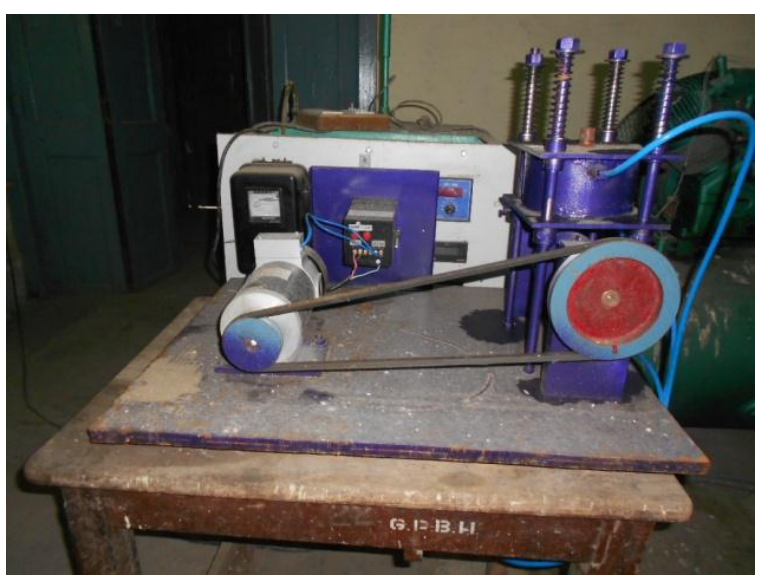

Fig.4: Experimental set up

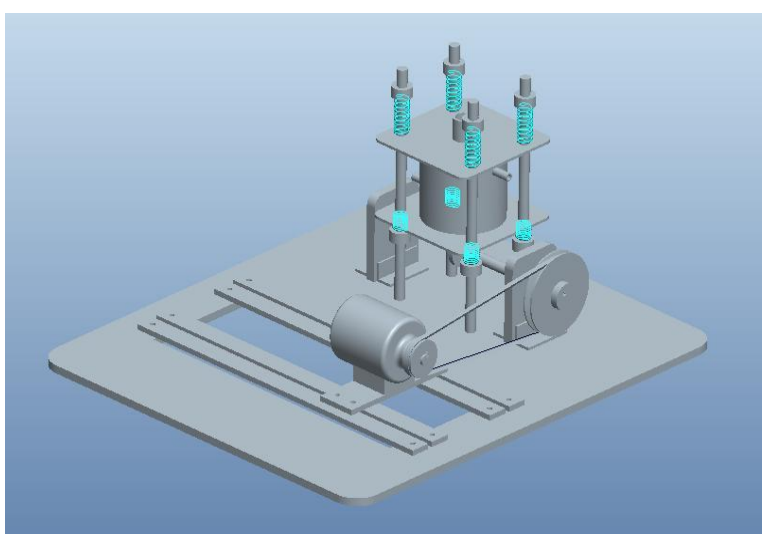

Fig.5: View of Experimental set up

Other operating specific are as follow:

1] Max. Working pr. $=5$ to $12 \mathrm{~kg} / \mathrm{cm}^{2}$

2] Design pressure $=60 \mathrm{~kg} / \mathrm{cm}^{2}$

3] Factor of safety $=6$

4] Stress across section of pipe is uniform (when $d / t>20$ )

5] Design material = mild steel

6] Allowable stress $=700 \mathrm{~kg} / \mathrm{cm}^{2}$

Thickness of the cylinder can be found by Lames equation $\mathrm{t}=1 / 2[\{(\mathrm{f} 1+\mathrm{P}) /(\mathrm{f} 1-\mathrm{P})\}-1]^{1 / 2}$

$=1 / 2[\{(\mathrm{f} 1+60) /(\mathrm{f} 1-60)\}-1]^{1 / 2}$

$=2.16 \mathrm{~mm}$

On the safe we will use thickness of cylinder as $3 \mathrm{~mm}$. 


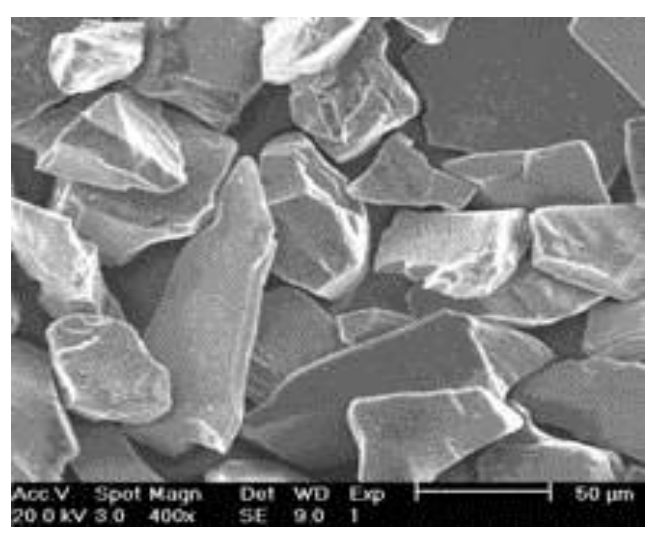

Fig.6: Photograph of sea sand

Specification of sea sand

Silica sand:

Grain size $\quad=100-150$ micron

Physical specification $=1.0-2.5 \mathrm{~mm}$

Uniform coefficient $=1.3-1.7$

Specific gravity $\quad=2.67$

Mohr's Hardness $\quad=7$

Density $\quad=105-115 \mathrm{lbs} /$ foot cubic

\section{Observation Table}

1) Nozzle a) Material $=$ Mild steel b) Diameter $=2.0 \mathrm{~mm}$

2) Abrasive a) Material = aluminum oxide b) Grain Size

= 100-150 $\mu \mathrm{m}$

3) Work piece a) Material = Glass b) Thickness =2 $\mathrm{mm}$

Abbreviation used in this paper is

MRR-material removal rate $\mathrm{gm} / \mathrm{sec}$

PFR-powder flow rate $\mathrm{gm} / \mathrm{sec}$

SOD - standoff distance in $\mathrm{mm}$

DOC-Depth of cut in $\mathrm{mm}$

p- Pressure in $\mathrm{kg}$ per sq $\mathrm{cm}$.

Table .1 observations for Mild steel Nozzle and abrasive

\begin{tabular}{|l|l|l|l|l|l|}
\hline $\begin{array}{l}\text { Sr. } \\
\text { No }\end{array}$ & $\begin{array}{l}\mathrm{P} \\
\mathrm{Kg} / \mathrm{cm} \\
2\end{array}$ & $\begin{array}{l}\text { SOD } \\
\mathrm{mm}\end{array}$ & $\begin{array}{l}\text { MRR } \\
\mathrm{W} / \mathrm{T}= \\
\mathrm{gm} / \mathrm{sec})\end{array}$ & $\begin{array}{l}\mathrm{PFR} \\
\mathrm{Wa} / \mathrm{T}= \\
\mathrm{gm} / \mathrm{sec}\end{array}$ & $\begin{array}{l}\text { DOC } \\
\mathrm{mm}\end{array}$ \\
\hline 1 & 5 & 5 & 0.042 & 1.06 & 4.5 \\
\hline 2 & 5.5 & 6 & 0.042 & 1.16 & 4.95 \\
\hline 3 & 6 & 7 & 0.046 & 1.24 & 5.55 \\
\hline 4 & 6.5 & 8 & 0.050 & 1.43 & 5.86 \\
\hline 5 & 7.0 & 9 & 0.060 & 1.51 & 6.10 \\
\hline
\end{tabular}

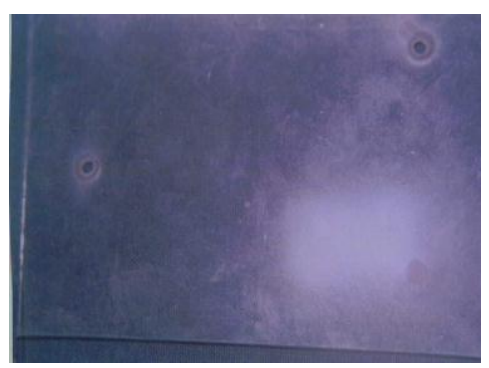

Fig.7: DOC of mild steel Nozzle

\section{5 .Result and Discussion}

The graph shows performance characteristic of MRR v/s PFR good fit for cubic polynomials where $\mathrm{R}$ square value is 0.9687 and the linear model for polynomial is $\mathrm{f}(\mathrm{x})=$ $\mathrm{p} 1 * \mathrm{x}^{\wedge} 3+\mathrm{p} 2 * \mathrm{x}^{\wedge} 2+\mathrm{p} 3 * \mathrm{x}+\mathrm{p} 4$ where Coefficients (with $95 \%$ confidence bounds) value of $\mathrm{p}$ are $\mathrm{p} 1=0.4976$, $\mathrm{p} 2=-1.803, \mathrm{p} 3=2.183, \mathrm{p} 4=-0.8392$

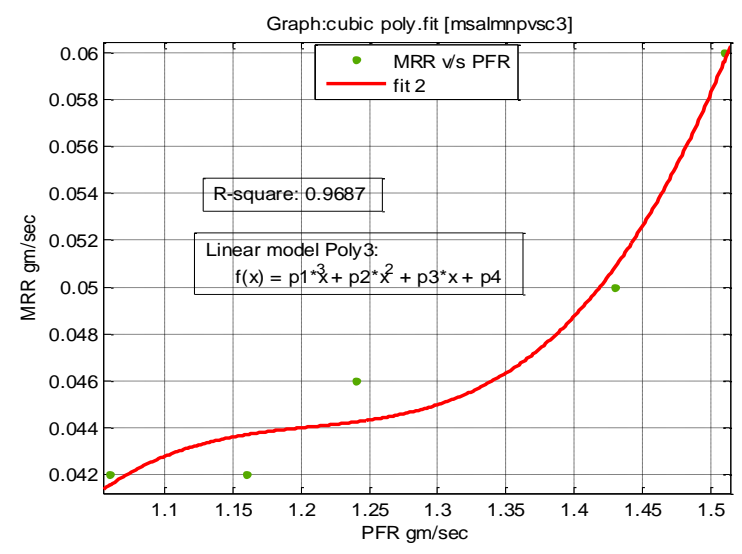

Fig.8: MRR v/s PFR

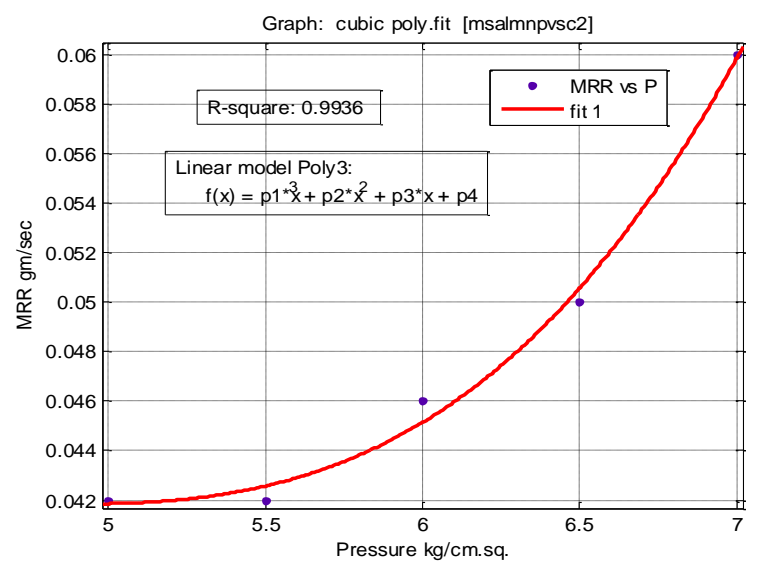

Fig.9: MRR v/s Pressure

\section{Analysis}

Analysis of above cubic polynomial with the $95 \%$ prediction bounds are as follows by using $1^{\text {st }}$ degree of derivation and $2^{\text {nd }}$ degree of derivation.

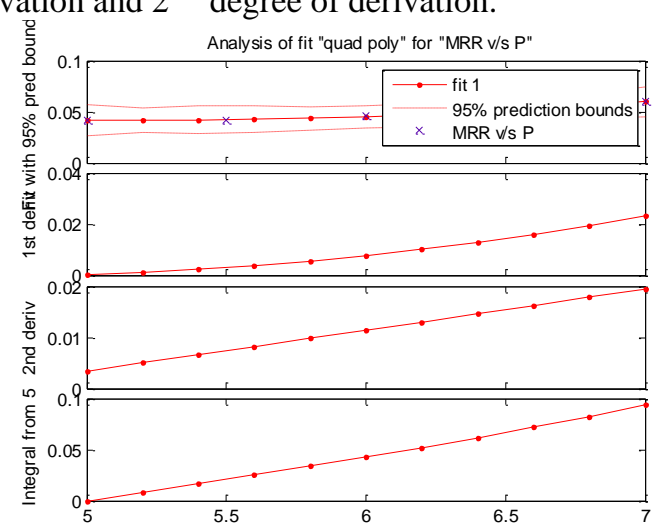

Fig .10: Analysis of fit for MRR v/s Pressure 


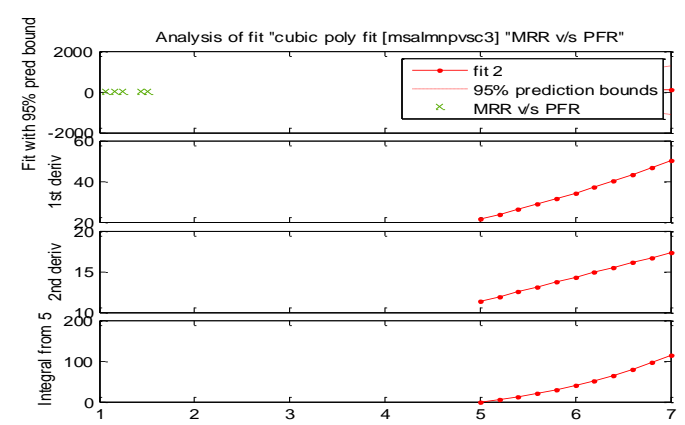

Fig.11: Analysis of fit for MRR v/s PFR

\section{Conclusion}

1] As the pressure increases the material removal rate increases because of the increasing energy available for erosion.

2] The abrasive particles from the nozzle follow a parallel path only if pressure is increasing.

3] The powder flow rate is increasing as pressure increases because of proper mixing.

4] Life of mild steel nozzle is lesser than traditional nozzle as it is less hardness.
5] Sticking charecterstic at corner is minimized due to cylindrical in shape, gives the proportionate mixing of sand abrasive and compressed air.

\section{References}

R. Balasubramaniam, J. Krishanan, N. Ramkrishanan, (2002), A study of shape of surface generated by abrasive jet machining, ELSEVIER, the journal of material processing technology 121 pg 102-106.

A.EI- Domiaty, H.M.Abd EI-Hafez, and M.A.shaker, (2009) drilling glass sheet by abrasive jet machining, world academic science engineering and technology 56, 61-67

Adnan Akkurt, (2009) the effect of material type and plate thickness on drilling time of abrasive water jet drilling process , ELSEVIER, the journal of material and design $30 \mathrm{pg} 810$ 81

A.A.Khan, M.M. Haque, (2007) performance of different abrasive material during abrasive water jet machining of glass, ELSEVIER, the journal of material processing technology 191, pg 404-40

P.K.Ray, A.K.Paul ,(2 Nov 1997) some studies on abrasive jet machining, the journal of institution of engineer (India), vol 68,pg 27-30, 